\title{
Acute compartment syndrome after muscle rupture in a non-athlete
}

Scarborough General Hospital, Scarborough A S Thennavan

L Funk

A P Volans

Correspondence to: Mr Funk, 39 Bottom o' th' Moor, Horwich, Lancs BL6 6QF.

Accepted 20 March 1999

\author{
A S Thennavan, L Funk, A P Volans
}

\begin{abstract}
Acute compartment syndrome after muscle rupture, although rare, is a limb threatening condition, which warrants emergency treatment. The case of acute compartment syndrome secondary to a gastrocnemius muscle tear of the right lower leg, in a non-athlete is reported. To our knowledge, this is the only description of acute compartment syndrome due to muscle rupture in a non-athlete.

( Accid Emerg Med 1999;16:377-378)
\end{abstract}

Keywords: compartment syndrome; non-athlete; muscle rupture

\section{Case report}

A 47 year old white male farmer walked into the accident and emergency (A\&E) department complaining of progressive swelling in his right calf, mild pain, and cold right foot after a jump of about 3-4 feet off a tractor nine hours earlier. He had not taken any analgesia for the pain and he carried on with the routine farm work. He was otherwise fit and well. He was not on any medication.

On examination, he had a tensely swollen right calf, which was $6 \mathrm{~cm}$ greater in diameter than the left calf. He had surprisingly little pain when performing active or passive movements of the right ankle and foot. Simmond's test suggested intact calf musculature and tendocalcaneus. The dorsalis pedis pulsation was not palpable but was detected with Doppler. The posterior tibial pulsation was palpable but feeble. Sensation was diminished in the distribution of the sural nerve.

Lower leg compartment pressures were measured in the A\&E department, using Whiteside's technique. ${ }^{1}$ The following pressures were found: $70 \mathrm{~mm} \mathrm{Hg}$ in the anterior compartment, $40 \mathrm{~mm} \mathrm{Hg}$ in the lateral compartment, and $70 \mathrm{~mm} \mathrm{Hg}$ in the posterior compartment. His blood pressure was $130 / 90$ $\mathrm{mm} \mathrm{Hg}$.

Radiography did not demonstrate any bony injuries. White cell count was raised at $13 \times$ $10^{9} / 1$. Routine biochemistry and coagulation studies were normal.

The clinical diagnosis of advanced acute compartment syndrome was made. The patient was taken to the theatre immediately for fasciotomies. All three lower leg compartments were decompressed through medial and lateral incisions. The medial head of gastrocnemius was found to have ruptured at the musculotendinous junction. All the muscles were viable. The patient returned to theatre three times over the next week for the wound exam- ination and progressive, direct wound closure. $\mathrm{He}$ was discharged from hospital after eight days, and proceeded to make a full recovery.

\section{Discussion}

Compartment syndrome is defined as the elevation of interstitial pressure in closed fascial compartment that results in microvascular compromise. Compartment syndrome is a potentially serious complication of extremity trauma. ${ }^{1}$

Prolonged elevation of tissue pressure in a closed compartment results in myoneural hypoxia. Bleeding within the compartment or oedema may cause this raised pressure. This in turn causes reduced blood flow through the compartment, which increases the hypoxia, reduces cell function and increases the likelihood of further oedema. Tissue pressure can rise sufficiently to reduce tissue perfusion below that required for tissue viability.

The characteristic presentation of compartment syndrome is pain out of proportion to the perceptible injury, which is worsened by passive stretching of the involved muscles. ${ }^{1}$ Late signs are paresis and parasthesia by which time permanent tissue damage is likely. The diagnosis of compartment syndrome can be difficult, especially where a low trauma injury occurs and the patient has a high pain tolerance, as in this case. The diagnosis may be aided by the measuring of the relevant compartment pressures.

Both experimental and clinical experience has demonstrated that normal pressure within the closed compartment is $0 \mathrm{~mm} \mathrm{Hg}$. This pressure increases significantly in compartment syndrome. Fasciotomy is usually indicated if the pressure raises above 40 to $45 \mathrm{~mm}$ $\mathrm{Hg}$ in a patient who has diastolic blood pressure of $70 \mathrm{~mm} \mathrm{Hg}$ and any signs or symptoms of compartment syndrome. ${ }^{1}$ McQueen and Court-Brown recommend that decompression should be performed when the compartment pressure approaches to within $30 \mathrm{~mm} \mathrm{Hg}$ of the diastolic. ${ }^{2}$ Other authors have quoted absolute figures ranging between 30 and $60 \mathrm{~mm} \mathrm{Hg}^{3-6} \mathrm{~A}$ definite indication for fasciotomy is tissue pressure that equals or exceeds the diastolic pressure. It is generally accepted that surgery is performed as soon as possible.

Compartment syndrome may be acute or chronic in onset, depending on the aetiology. Acute compartment syndrome is usually a result of direct trauma and may occur in athletes and non-athletes, depending on the cause. Chronic compartment syndrome is the result of repetitive indirect muscle trauma and occurs mainly in athletes. 
Acute compartment syndrome may be a result of any trauma to the limb. The trauma is usually a result of an open or closed fracture of the bones, or a crush injury to the limb. Other causes include haematoma, gun shot or stab wounds, animal or insect bites, post-ischaemic swelling, vascular damage, electrical injuries, burns, prolonged tourniquet times, etc. Other causes of compartment syndrome are genetic, iatrogenic, or acquired coagulopathies, infection, nephrotic syndrome or any cause of decreased tissue osmolarity and capillary permeability.

Chronic compartment syndrome is most typically an exercise induced condition characterised by a relative inadequacy of musculofascial compartment size producing chronic or recurring pain and/or disability. It is seen in athletes, who often have recurring leg pain that starts after they have been exercising for some time. There is no history of trauma. The pain is localised to the involved muscles or the entire compartment and the symptoms are very similar to acute compartment syndrome. The symptoms often settle with rest, however if the athlete returns to his sport after laying off, the symptoms usually recur. The treatment of confirmed chronic compartment syndrome is a surgical fasciotomy of the affected compartments.

Essentially, any cause of increased compartment pressure can result in a compartment syndrome. Muscle rupture has been implicated in causing increased compartment pressures in athletes after severe exercise. The diagnosis of acute compartment syndrome due to rupture of the body of gastrocnemius has been reported in athletes. ${ }^{78}$ This, however, is the first reported case of acute compartment syndrome caused by a gastrocnemius muscle rupture in a non-athlete.

\section{Conclusion}

Soft tissue injuries and muscle tears occur frequently in athletes. Most injuries result from direct trauma. Indirect trauma resulting in muscle tears and ruptures can cause acute compartment syndrome in athletes. It is also important to keep in mind the possibility of similar injuries in a non-athlete as well. More research is needed to define optimal management patterns and potential strategies for injury prevention.

Conflict of interest: none.

Funding: none.

1 Mabee JR, Bostwick TL. Pathophysiology and mechanisms of compartment syndrome. Orthopaedic Reviews 1993;17580.

2 McQueen MM, Court-Brown CM. Compartment monitoring in tibial fractures-the pressure threshold for decoming in tibial fractures-the pressure threshold

pression. F Bone foint Surg Br 1995;78:99-104.
3 Blick SS, Brumback RJ, Poka A, et al. Compartment Blick SS, Brumback RJ, Poka A, et al. Compartment
syndrome in open tibial fractures. $\mathcal{f}$ Bone foint Surg Am syndrome in open

4 Hargens AR, Akeson WH, Mubarak SJ, et al. Tissue fluid pressures: from basic research tools to clinical applications. $\Im$ Orthop Res 1989;7:902-9.

5 Matsen FA III, Winquist RA, Krugmire RB Jr. Diagnosis and management of compartmental syndromes. $\mathcal{f}$ Bone foint Surg Am 1980;62:286-91.

6 Mubarak SJ, Owen CA, Hargens AR, et al. Acute compartment syndromes: diagnosis and treatment with the aid of the wick catheter. F Bone foint Surg Am 1978;60:1091-5.

7 Mohanna PN, Haddad FS. Acute compartment syndrome following non-contact football injury. $\mathrm{Br} \mathcal{f}$ Sports Med 1997;31:254-5.

8 Best TM. Soft-tissue injuries and muscle tears. Clin Sports Med 1997;16(30):419-34.
Accident and

Emergency

Department, John

Radcliffe Hospital,

Oxford

R A Kotnis

J C Halstead

P J Hormbrey

Correspondence to: Dr Rohit A Kotnis,

Department of Accident and Emergency, John Radcliffe

Hospital, Headington

Oxford OX3 3DU.

Accepted 29 April 1999

\section{Atraumatic bilateral Achilles tendon rupture: an association of systemic steroid treatment}

\author{
R A Kotnis, J C Halstead, P J Hormbrey
}

care treatment two months previously, after which he had been started on oral prednisolone. His respiratory symptoms were well controlled at the time of presentation. There was no history of any tendon or joint pathology before the steroid treatment.

Examination revealed a palpable gap in his left Achilles tendon $2 \mathrm{~cm}$ proximal to the insertion on the calcaneum. A diagnosis of ruptured Achilles tendon was made and the patient was placed in an equinus plaster of Paris below knee cast. The next day repair of the tendon under local anaesthetic was performed utilising an open technique; at surgery the tendon appeared degenerate. The equinus cast was reapplied with a plan to change to the mid-equinus position in two weeks and then to a Samson boot for mobilisation of the ankle within four weeks. 